\title{
LA DANZA EN LA ESCUELA Y LA FORMACIÓN DE LOS PROFESORES
}

\author{
Herminia García Ruso \\ Universidad de Santiago de Compostela
}

\begin{abstract}
RESUMEN. En la Ley Orgánica 1/1990 de 3 de octubre, de Ordenación General del Sistema Educativo (LOGSE) el sistema educativo comprende las enseñanzas de régimen general y las enseñanzas de régimen especial. La Danza está incluida en las enseñanzas de régimen especial dentro de las enseñanzas artísticas junto con la música, el arte dramático, las artes plásticas y el diseño. El objetivo de este artículo es analizar el tratamiento que tiene la Danza en las eneñanzas de régimen general. Para ello, intentaremos resaltar la incoherencia que hay entre las áreas de la educación primaria, que serán obligatorias y tendrán un carácter global e integrador, y la formación de los futuros maestros.
\end{abstract}

ABSTRACT. In Organic Law 1/1990 of 3rd October of the general arrangement of the educational system (LOGSE), the educational system includes the general regime education and the special regime education. Dance is included in the special regime as part of the artistic disciplines together with music, drama, the plastic arts and design. The aim of this article is to analyse the treatment given to Dance in the general regime. Thus, we will try to emphasize the inconsistency that exists between the areas of primary education, which will be obligatory and will have a global and integrated character, and the training of future teachers.

\section{Introducción}

Con este artículo queremos poner de manifiesto el tratamiento que tiene la Danza en el sistema educativo centrándonos, fundamentalmente, en la etapa de educación primaria. Para ello, analizaremos los aspectos más relevantes que recoge la LOGSE con relación a la Danza y su presencia en los currículos de educación primaria y secundaria.

La revisión de los documentos oficiales nos sugiere, básicamente, tres cuestiones: la primera, es saber que modelo de profesional es el idóneo para impartir de manera globalizada el área de educación artística en la educación primaria; la segunda, discernir lo que podría ser relevante y útil para mejorar la formación de los profesores encargados de dar dicha área; y tercero, reflexionar sobre el tratamiento que tiene la Danza en el sistema educativo. 
Seguidamente, argumentamos cada uno de los aspectos aludidos bajo los epígrafes de la formación de los profesores y de la Danza en las eseñanzas de regimen general del sistema educativo. Finalmente, exponemos a modo de conclusión que el gran reto, para que la Danza tenga el tratamiento que se merece en la educación, está en preparar profesores cualificados en el área de educación artística.

\section{Ley Orgánica 1/1990 de 3 de octubre, de Ordenación General del Sistema Educativo}

Haciendo un breve recorrido por la historia de la Danza podemos observar cómo la enseñanza de la Danza ha estado ligada a la enseñanza de la Música y a la de Arte Dramático. La promulgación de la Ley Orgánica 1/1990 de 3 de octubre, de Ordenación General del Sistema Educativo (LOGSE) y su siguiente desarrollo, por medio de los Reales Decretos 755/1992, 1254/1997 y 1463/1999, en los que se establecen los aspectos básicos del currículo de las enseñanzas del grado elemental, medio y superior, respectivamente, supuso un avance muy importante en la regulación de la eneñanza de la Danza. Con la LOGSE se pretende dar una respuesta adecuada a las demandas del presente y del futuro de los ciudadanos. Para ello, se prolonga la educación básica y obligatoria, se organiza el sistema educativo en nuevas etapas y niveles; se le da un nuevo enfoque a la formación profesional, ligándola al mundo laboral; se diversifica la enseñanza con las modalidades de artes, tecnología, ciencias de la naturaleza y de la salud, humanidades y ciencias sociales; se aborda, por primera vez en el contexto de una reforma del sistema educativo, una regulación extensa de las enseñanzas de la Música, del Arte Dramático y de las Artes Plásticas; se recoge que el objetivo primero y fundamental de la educación es el de proporcionar a los niños/as, a los jóvenes de ambos sexos, una formación plena que les permita conformar su propia y esencial identidad; se considera la formación del profesorado como un derecho y una obligación del profesor, así como una responsabilidad de las Administraciones Educativas.

En el artículo 14 de la citada Ley se señala que la educación primaria comprenderá tres ciclos de dos cursos académicos cada uno y se organizará en áreas que serán obligatorias y tendrán un carácter global e integrador. Las áreas a las que hace referencia son las siguientes:

- Educación artística.

- Educación física.

- Lengua castellana, lengua oficial de la Comunidad Autónoma y literatura.

- Lenguas extranjeras.

- Conocimiento del medio natural, social y cultural .

- Matemáticas.

En el artículo 16 se recoge textualmente que la educación primaria será impartida por maestros, que tendrán competencia en todas las áreas de este nivel. La enseñanza de la música, de la educación física, de los idiomas extranjeros o de aquellas enseñanzas que se determinen, serán impartidas por maestros con la especialidad correspondiente. Ante esta perspectiva definida de esta manera no podemos sino sorprendernos al comprobar que, en función de ello, por el Real Decreto 1440/1991, se 
establece el título universitario oficial de Maestro en sus diversas especialidades y las directrices generales propias de los planes de estudios conducentes a su obtención. Pero resulta paradójico que dentro de las especialidades del título oficial de Maestro no figure la especialidad de artística y sí figure la especialidad en educación musical cuando, en la educación primaria, la música es una de las materias integradas en el área de la educación artística junto con la plástica y la dramatización. Lamentablemente ¿qué pasa con la plástica, la danza y la dramatización?. A este análisis de la situación habría que añadir otra serie de apreciaciones a tener en cuenta, tales como el planteamiento que en los documentos oficiales tiene la educación artística en la educación primaria. En el Diseño Curricular Base de la educación primaria se reconoce explícitamente que la educación artística, en esta etapa educativa, debe tener un enfoque globalizado.

La Educación Primaria, debería potenciar el desarrollo de las capacidades que están en la base de la realización de los procesos básicos: el de la expresión de sentimientos e ideas, y de la percepción de representaciones plásticas, musicales y dramáticas. Ambos aspectos se encuentran íntimamente interrelacionados y se llaman uno a otro en la dimensión comunicacional del proceso artístico.

[...] Otras razones pueden alegarse todavía a favor de la inclusión en una sola área de los distintos modos de expresión y representación artística. Las conexiones entre la dramatización y la danza, por ejemplo, son evidentes. Pero más allá de esta vecindad de unas artes con otras, conviene destacar que todos los intentos de un arte -en algún sentido- "total", desde la opera o el ballet, en algunos de sus formatos hoy ya clásicos, hasta las propuestas más recientes y avanzadas de un espacio escénico, o de espectáculo, todo él cargado de mensajes y significantes plásticos, a la vez que de acontecimientos sonoros, con un tratamiento del cuerpo humano como elemento escultórico en movimiento, coinciden en borrar fronteras entre los distintos géneros convencionales de arte y en incorporar, en distintos modos y medidas, componentes clásicamente pertenecientes a distintas artes: el espacio, el volumen, la forma, el color, el movimiento del cuerpo humano, el sonido musical y el ritmo. (MEC 1999, pp. 150-154)

Sin necesidad de más detalles esta larga cita nos sugiere fundamentalmente tres cuestiones, la primera es que modelo de profesional es el idóneo para dar de manera globalizada el área de Educación Artística en la educación primaria; la segunda, discernir lo que podría ser relevante y útil para mejorar la formación de los profesores encargados de impartir dicha área; y la tercera, reflexionar sobre el tratamiento que tiene la Danza en el sistema educativo.

\section{La formación de los profesores}

Respecto a la formación de los profesores cabe resaltar que el nuevo perfil del profesor, se aproxima más al de un profesional reflexivo y crítico, que al de mero ejecutor de técnicas y destrezas de enseñanza. Desde esta conceptualización, la formación del profesor debiera ir enfocada, desde nuestro punto de vista, hacia la preparación del futuro docente en las habilidades y estrategias que le permitan enjuiciar las metas educativas, tomar decisiones sobre qué métodos de enseñanza y qué contextos conducen a ellas. Las tomas de decisiones que los profesores adoptan antes, durante y después del acto didáctico, están prefiguradas por una previa socialización en su rol 
de alumno, una formación psicopedagógica, el establecimiento de una base centífica y metodológica... proyectado sobre las actividades que se van a realizar, los contenidos, materiales didácticos y el contexto organizativo. Si tomamos como punto de referencia de la calidad de la enseñanza la formación de los profesores, sería relevante pararse a pensar en cuales deberían ser los componentes del conocimiento profesional. Al igual que Marcelo (1994,p.252), utilizamos el término conocimiento para referirnos no sólo a los conocimientos conceptuales, sino también a los procedimientos y al saber justificar el porqué de las acciones. El conocimiento pedagógico general, el conocimiento del contenido, el conocimiento didáctico del contenido y el conocimiento del contexto, son considerados por diferentes autores (Grossman,1990; Marcelo,1994; Shulman,1986, 1987; Tinning,1993) como los componentes del conocimiento profesional.

- El conocimiento pedagógico general esta relacionado con la enseñanza y aprendizaje del alumno, con las teorías del desarrollo humano, con los principios generales de la enseñanza, con el conocimiento acerca de las técnicas didácticas, con la estructura y gestión de las clases, con la planificación curricular, con la cultura social e influencias del contexto en la enseñanza, con la historia y filosofía de la educación, etc. En los planes de estudio de magisterio estos contenidos forman parte de las materias troncales, adscritas a las áreas de conocimiento de Didáctica y Organización Escolar, de Teoría e Historia de la Educación y Psicología Evolutiva y de la Educación.

- El conocimiento del contenido hace referencia al conocimiento de la materia a enseñar, que a su vez, incluye diferentes componentes. Marcelo (1994), reúne distintas clasificaciones de varios autores y considera como los componentes más representativos: el conocimiento sustantivo del contenido, que recoge el cuerpo de conocimientos generales de la materia, y el conocimiento sintáctico del contenido, que completa al anterior, y está relacionado con el dominio, por parte del profesor, de los paradigmas de investigación en cada disciplina. Con relación a la Educación Artística, consideramos que, en la selección de los contenidos de los títulos oficiales de magisterio, no se cumple el criterio básico representado por las necesidades implicadas en la propia profesión. En este campo, quien lleva la iniciativa sobre cuales son las necesidades que un Plan de Estudios debe satisfacer, es el propio Ministerio de Educación y las Consejerías de Educación de las Comunidades Autónomas. En tal sentido, echamos en falta un especialista en Educación Artística. En la actualidad los maestros de educación primaria tienen que impartir por decreto el área de Educación Artística sin tener ninguna formación específica ni en Danza ni en Dramatización. Basta echar una mirada a los planes de estudio de los futuros profesores de educación primaria, para percatarse que la Educación Plástica, la Dramatización y la Danza no tienen el tratamiento que se merecen.

- El conocimiento didáctico del contenido hace referencia a la capacidad del profesor para transformar el contenido del conocimiento que él posee, dentro de las formas pedagógicamente eficaces y adaptadas a las variaciones de la capacidad y experiencia de los alumnos. Para Shulman, (1992,p.12), este tipo de conocimiento no es exclusivamente técnico, ni sólamente reflexivo. No es sólo el conocimiento 
del contenido, ni el dominio general de métodos de enseñanza. Es una mezcla de todo lo anterior, y es principalmente pedagógico.

- El conocimiento del contexto hace referencia al dónde y al quien se enseña, es decir, al contexto de la práctica docente representado por el centro escolar, los alumnos y los profesores.

Como responsables, en cierta medida, de la formación de los maestros de educación primaria debemos tener presente el nuevo escenario profesional de los futuros docentes, a la hora de definir los componentes del conocimiento profesional y de elaborar, en parte, los nuevos planes de estudio. No ha lugar a analizar los nuevos planes de estudio, para la formación del profesorado de educación primaria. Sin embargo, consideramos ineludible realizar algunas reflexiones acerca de los mismos. La selección de los contenidos que debe adquirir y desarrollar el profesor como base de su labor docente, ha sido y sigue siendo una cuestión esencial, compleja y condicionada por un buen número de factores de orden político, económico, cultural e idelógico.

La estructura formativa de los planes de estudios de magisterio, gira alrededor de tres ejes, a saber: formación científico cultural, psicopedagógica y el practicum. Desde nuestro punto de vista, esta estructura formativa puede ser adecuada si se tiene en cuenta el papel que el futuro profesor ha de desempeñar en el ejercicio de su profesión y se apoya en los pilares del conocimiento pedagógico general, del conocimiento del contenido, del conocimiento didáctico y del conocimiento del contexto. Combinar el peso que deben soportar estos cuatro pilares tomando en consideración, además, los supuestos en los que se fundamenta el modelo de formación del profesorado, va a ser lo que, en definitiva, dará al curriculum del maestro un estilo peculiar. Sin embargo, nos parece un plan demasiado ambicioso, por lo arduo y complejo que supone, en tres cursos escolares, el formar un maestro y a su vez un especialista. Con estos nuevos planes de estudios probablemente no se alcance el objetivo pretendido de formar un maestro que, además, domine a un cierto nivel el propio ámbito de su especialidad. Al hilo de lo que precede, Pérez Gómez (1993) arguye:

La formación inicial del profesor de Educación Infantil y Primaria sigue recluida en el nivel de Diplomatura, donde se sitúan las carreras correspondientes a las técnicas intermedias cuya función no se considera autónoma profesionalmente sino dependiente de profesionales que acceden al conocimiento, explican los fenómenos y derivan normas de intervención que los primeros se encargan de aplicar. No es ésta la imagen del profesor como profesional autónomo.(p.50)

El nuevo profesor no puede limitarse a ser un reproductor de programaciones preestablecidas, sino que debe ser un generador constante de currículum, lo cual supone redefinir el concepto de competencia docente y la formación que este profesor ha de recibir. No podemos exigirle a los maestros que impartan, con cierto nivel y de manera globalizada, el área de Educación Artística cuando la formación que ellos reciben esta enfocada hacia una parcela de la educación artística y no al área de artística como tal. 


\section{La Danza en las enseñanzas de régimen general del sistema educativo}

Respecto al posicionamiento y tratamiento que el sistema educativo da al tema de la Danza, dentro de las enseñanzas de régimen general, conviene precisar que ésta aparece recogida en el Diseño Curricular Base de Primaria (DCB), de manera general, dentro del área de Educación Artística y del área de Educación Física.

En el área de Educación Artísica, es en el bloque de contenidos: Movimiento Rítmico y Danza donde se abordan todos los contenidos que tratan la relación entre la música y el movimiento corporal. Definiendo su importancia y función en los términos siguientes:

Este bloque resulta de especial importancia durante los primeros ciclos de la etapa cuando conviene diversificar las actividades para desarrollar las distintas capacidades motrices, fomentar las relaciones interpersonales, los estados afectivos y la capacidad de reaccionar físicamente a la música.

El movimiento y la Danza deberían de capacitar no sólo para adquirir unas destrezas rítmicas sino también para alcanzar esa necesidad de expresión y comunicación que toda educación estética debe desarrollar. (MEC1989, p. 183).

En el área de Educación Física, la Danza figura dentro del bloque de contenidos: El Cuerpo: Expresión y comunicación. En el DCB se dice que el cuerpo y el movimiento son medios de expresión y de comunicación y se señala al repecto:

La enseñanza de la Educación Física incorpora estos contenidos incidiendo más en los aspectos expresivos del movimiento y en la utilización funcional del propio cuerpo, mientras que en otras áreas lo harán en el componente de dramatización y comunicación. [...] Este eje incluye el lenguaje corporal, que incorpora los contenidos propios de los leguajes (comprensión y expresión, en este caso corporal), y el movimiento expresivo, con contenidos normalmente de baile, rítmica, expresión corporal, y, en general, propuestas de movimiento con un alto componente de plasticidad y creatividad que incorporan cualidades expresivas del movimiento como gravedad, lentitud, rapidez, ritmo, ligereza, etc., para mejorar su capacidad expresiva. (MEC 1989, p. 219)

Hasta ahora hemos hecho alusión a la importancia y función de los contenidos referidos a la Danza, dentro del área de Educación Artística y del área de Educación Física. Vamos a exponer, a continuación, los tres tipos de contenidos que se recogen en el bloque Movimiento Rítmico y Danza y en el bloque el cuerpo: expresión y comunicación, en las respectivas áreas, citadas, del DCB. 
LA DANZA EN LA ESCUELA Y LA FORMACIÓN DE LOS PROFESORES

BLOQUE. MOVIMIENTO RÍTMICO Y DANZA

\begin{tabular}{|c|c|c|}
\hline $\begin{array}{l}\text { HECHOS, CONCEPTOS } \\
\text { PRINCIPIOS }\end{array}$ & PROCEDIMIENTOS & $\begin{array}{c}\text { ACTITUDES, VALORES Y } \\
\text { NORMAS }\end{array}$ \\
\hline $\begin{array}{l}\text { 1. El movimiento expresivo } \\
\text { y la música: formas bási- } \\
\text { cas. } \\
\text { 2. La Danza como forma } \\
\text { organizada de movi- } \\
\text { miento. } \\
\text { 3. Tipos de Danza }\end{array}$ & $\begin{array}{l}\text { 1. Utilización de un reper- } \\
\text { torio de danzas y ritmos } \\
\text { fijados e inventados. } \\
\text { 2. Improvisación de pasos y } \\
\text { fórmulas rítmicas bási- } \\
\text { cas. } \\
\text { 3. Interpretación del movi- } \\
\text { miento adecuado al } \\
\text { ritmo y al sentido musi- } \\
\text { cal de la danza. } \\
\text { 4. Comprensión de la } \\
\text { Danza. }\end{array}$ & $\begin{array}{l}\text { 1. Disposición para probar } \\
\text { diferentes ritmos mos- } \\
\text { trando las propias habili- } \\
\text { dades en este campo. } \\
\text { 2. Tendencia a mejorar los } \\
\text { recursos propios con la } \\
\text { ayuda de las técnicas } \\
\text { que el maestro ofrezca. } \\
\text { 3. Constancia en el ensayo } \\
\text { de pasos de danza y } \\
\text { movimientos con el obje- } \\
\text { tivo de mejorar su ejecu- } \\
\text { ción . } \\
\text { 4. Valoración de la danza } \\
\text { como vehículo de expre- } \\
\text { sión y comunicación. } \\
\text { 5. Interés por conocer y } \\
\text { valorar las manifestacio- } \\
\text { nes culturales pertinentes } \\
\text { en este ámbito y también } \\
\text { las de la comunidad a la } \\
\text { que pertenece. }\end{array}$ \\
\hline
\end{tabular}

(MEC 1989, pp.183-184) 
HERMINIA GARCÍA RUSO

\section{BLOQUE. EL CUERPO: EXPRESIÓN Y COMUNICACIÓN}

\begin{tabular}{|c|c|c|}
\hline $\begin{array}{c}\text { HECHOS, CONCEPTOS Y } \\
\text { PRINCIPIOS }\end{array}$ & PROCEDIMIENTOS & $\begin{array}{c}\text { ACTITUDES, VALORES Y } \\
\text { NORMAS }\end{array}$ \\
\hline $\begin{array}{l}\text { 1. El cuerpo: instrumento } \\
\text { de expresión y comuni- } \\
\text { cación: } \\
\text {. Recursos expresivos del } \\
\text { cuerpo: el gesto, el movi- } \\
\text { miento. } \\
\text { Tipos de posibilidades } \\
\text { asociadas al movimiento: } \\
\text { mímica, danza, dramati- } \\
\text { zación } \\
\text { 2. El ritmo como base tem- } \\
\text { poral, tempo y sonido } \\
\text { corporal. } \\
\text { 3. La calidad del movimien- } \\
\text { to y sus componentes. } \\
\text { 4. Relación entre lenguaje } \\
\text { expresivo corporal y } \\
\text { otros lenguajes. }\end{array}$ & $\begin{array}{l}\text { 1. Exploración y análisis de } \\
\text { las posibilidades y recur- } \\
\text { sos expresivos del propio } \\
\text { cuerpo. } \\
\text { 2. Utilización del gesto y el } \\
\text { movimiento para la } \\
\text { expresión, la representa- } \\
\text { ción y la comunicación } \\
\text { 3. Adecuación del movi- } \\
\text { miento a secuencias y rít- } \\
\text { mos, reproducción y } \\
\text { adaptación corporal a } \\
\text { bases temporales. } \\
\text { 4. Ejecución de ritmos y } \\
\text { bailes inventados, popu- } \\
\text { lares y tradicionales de } \\
\text { ejecución simple. } \\
\text { 5. Exploración e integra- } \\
\text { ción de la calidad del } \\
\text { movimiento en la propia } \\
\text { ejecución motriz y rela- } \\
\text { ciones con actitudes, } \\
\text { sensaciones y estados de } \\
\text { ánimo. } \\
\text { 6. Simbolización y codifi- } \\
\text { cación mediante el movi- } \\
\text { miento elaborado e } \\
\text { inventando respuestas } \\
\text { corporales. }\end{array}$ & $\begin{array}{l}\text { 1. Reconocimiento y valo- } \\
\text { ración de los usos expre- } \\
\text { sivos y comunicativos } \\
\text { del cuerpo. } \\
\text { 2. Valoración del movi- } \\
\text { miento de los otros anali- } \\
\text { zando los recursos } \\
\text { expresivos empleados, su } \\
\text { plasticidad y su intencio- } \\
\text { nalidad. } \\
\text { 3. Interés por mejorar la } \\
\text { calidad del propio movi- } \\
\text { miento. } \\
\text { 4. Participación en situacio- } \\
\text { nes que supongan comu- } \\
\text { nicación con otros, } \\
\text { utilizando recursos moto- } \\
\text { res y corporales. } \\
\text { 5. Desinhibición y esponta- } \\
\text { neidad. }\end{array}$ \\
\hline
\end{tabular}

(MEC 1989, pp. 231-232) 
En el Diseño Curricular Base de Educación Secundaria la consideración de la Danza es similar a la expuesta anteriormente para la Educación Primaria. La Danza figura en el área de Música formando parte del bloque de contenidos Movimiento y Danza en los términos que a continuación se detallan.

\section{BLOQUE. MOVIMIENTO Y DANZA}

\begin{tabular}{|c|c|c|}
\hline CONCEPTOS & PROCEDIMIENTOS & ACTITUDES \\
\hline $\begin{array}{l}\text { 1. El movimiento: } \\
\text { Factores del movimiento: } \\
\text { tiempo,peso, espacio y } \\
\text { flujo. } \\
\text {. Manifestaciones básicas: } \\
\text { locomoción, gestos, ele- } \\
\text { vación, rotación y posi- } \\
\text { ción. } \\
\text { Cualidades del movi- } \\
\text { miento: fuerza, veloci- } \\
\text { dad, y precisión } \\
\text { 2. El movimiento y la } \\
\text { danza: } \\
\text { Formas del movimiento: } \\
\text { libres y establecidas. } \\
\text { Elementos musicales: } \\
\text { ritmo, melodía, armonía } \\
\text { y forma. } \\
\text { Elementos de la danza: } \\
\text { pasos, figuras, agrupacio- } \\
\text { nes, acompañamiento } \\
\text { musical. } \\
\text { Formas espontáneas de } \\
\text { danza. } \\
\text { 3. Estilos y tipos de danza: } \\
\text { étnicas, clásicas, popula- } \\
\text { res, didácticas, modernas, } \\
\text { sociales y cortesanas. } \\
\text { 4. La danza como manifes- } \\
\text { tación cultural: contexto } \\
\text { histórico y social. } \\
\text { artes. }\end{array}$ & $\begin{array}{l}\text { 1. Profundización en la } \\
\text { práctica de las activida- } \\
\text { des básicas del movi- } \\
\text { mento (locomoción, } \\
\text { gestos, elevación, rota- } \\
\text { ción, y posición). } \\
\text { 2. Observación de Danzas } \\
\text { y formas de movimiento. } \\
\text { Comentario sobre las } \\
\text { mismas manejando el } \\
\text { vocabulario que les es } \\
\text { propio. } \\
\text { 3. Realización de juegos } \\
\text { populares, de animación } \\
\text { y de invención propia. } \\
\text { 4. Ejercitar la movilidad y la } \\
\text { habilidad corporal a tra- } \\
\text { vés de diferentes estilos } \\
\text { de danza. } \\
\text { 5. Utilización de un amplio } \\
\text { repertorio de danzas: } \\
\text { históricas, tradicionales, } \\
\text { didácticas y de salón. } \\
\text { 6. Elaboración y desarrollo } \\
\text { de coreografías. } \\
\text { 7. Improvisación de pasos y } \\
\text { movimientos según fór- } \\
\text { mulas rítmicas o melódi- } \\
\text { cas dadas. } \\
\text { 8ealización de grabacio- } \\
\text { nes para su utilización } \\
\text { como medio de obser- } \\
\text { vación y análisis de las } \\
\text { actividades de movi- } \\
\text { miento y danza. }\end{array}$ & $\begin{array}{l}\text { 1. Sensibilización de la } \\
\text { conciencia corporal. } \\
\text { 2. Valoración positiva tanto } \\
\text { de la actividad como del } \\
\text { reposo y la calma. } \\
\text { 3. Apertura y disfrute de las } \\
\text { diferentes manifestacio- } \\
\text { nes de danza y movi- } \\
\text { miento. } \\
\text { 4. Valoración del movi- } \\
\text { miento y la danza como } \\
\text { fuente de comunicación } \\
\text { y de expresión para sen- } \\
\text { tirse a gusto con uno } \\
\text { mismo, con los demás y } \\
\text { con el medio. } \\
\text { 5. Reconocimiento de } \\
\text { movimiento y la danza } \\
\text { como medio para enri- } \\
\text { quecer la percepción } \\
\text { visual y musical. }\end{array}$ \\
\hline
\end{tabular}


Analizando los contenidos conceptuales, procedimentales y actitudinales del bloque Movimiento y Danza, observamos que para impartirlos con cierto rigor académico se precisa tener una sólida formación en el campo del movimiento y de la Danza. En tal sentido, consideramos que los profesionales idóneos para realizar esta labor docente son los titulados superiores en Danza.

En el área de Educación Física la Danza está englobada dentro del bloque de Expresión Corporal, como se puede apreciar en el esquema siguiente.

\section{BLOQUE. EXPRESIÓN CORPORAL}

\begin{tabular}{|c|c|c|}
\hline CONCEPTOS & PROCEDIMIENTOS & ACTITUDES \\
\hline $\begin{array}{l}\text { 1. El cuerpo expresivo: las } \\
\text { posibilidades de expre- } \\
\text { sión y comunicación en } \\
\text { distintas manifestaciones } \\
\text { (mimo, danza, dramati- } \\
\text { zación, etc.). } \\
\text { 2. Técnica y significado del } \\
\text { uso de diversos paráme- } \\
\text { tros: intensidad, espacio } \\
\text { y tiempo. }\end{array}$ & $\begin{array}{l}\text { 1. Experimentación con la } \\
\text { respiración y relajación: } \\
\text { el espacio interior. } \\
\text { 2. Exploración y utilización } \\
\text { del espacio como ele- } \\
\text { mento de expresión } \\
\text { y comunicación: trayec- } \\
\text { torias, direcciones, am- } \\
\text { plitud, recogimiento, } \\
\text { desplazamientos, linea- } \\
\text { les y curvos.. } \\
\text { 3. Exploración y utilización } \\
\text { del tiempo como ele- } \\
\text { mento de expresión y } \\
\text { comunicación: la caden- } \\
\text { cia de movimientos, } \\
\text { intensidad (suave/fuerte), } \\
\text { la antítesis rápido/lento y } \\
\text { sus significados, etc. } \\
\text { 4. Investigación y práctica de } \\
\text { técnicas de distintas ma- } \\
\text { nifestaciones expresivas. } \\
\text { 5. Adquisición de habilida- } \\
\text { des expresivas. } \\
\text { 6. Elaboración y representa- } \\
\text { ción de composiciones } \\
\text { corporales indivi-duales } \\
\text { y corporales individuales } \\
\text { y colectivas. }\end{array}$ & $\begin{array}{l}\text { 1. Valoración del uso } \\
\text { expresivo del cuerpo y } \\
\text { del movimiento. } \\
\text { 2. Valoración de las pro- } \\
\text { ducciones culturales que } \\
\text { existen en el campo de la } \\
\text { expresión corporal y, en } \\
\text { general, valoración de la } \\
\text { expresividad y plastici- } \\
\text { dad en la ejecución de } \\
\text { cualquier tipo de movi- } \\
\text { miento. } \\
\text { 3. Desinhibición, apertura y } \\
\text { comunicación en las } \\
\text { relaciones con los otros. } \\
\text { Disposición favorable a } \\
\text { utilizar los hábitos de } \\
\text { respiración, relajación y } \\
\text { concentración como ele- } \\
\text { mentos de exploración } \\
\text { del espacio interior. }\end{array}$ \\
\hline
\end{tabular}

(MEC 1992b, pp.22-23)

El Real Decreto 3473/2000, de 29 de diciembre, que establece las enseñanzas mínimas correspondientes a la Educación Secundaria Obligatoria, desde nuestra pers- 
pectiva supone un paso atrás en los avances alcanzados por el anterior currículo abierto. Centrándonos en las áreas objeto de este estudio comentar que, en el área de Música, observamos que la Danza no se menciona dentro de los contenidos del área de Música, si bien, en los criterios de evaluación del tercer curso se hace referencia a la misma en los siguientes términos: reconocer las distintas manifestaciones de la danza y su evolución en el tiempo.

En el área de Educación Física desaparece el bloque de expresión corporal, algunos de los contenidos del mismo pasan a formar parte del bloque dedicado al Ritmo y Expresión. En nuestra opinión, los contenidos propuestos y secuenciados para los cuatro cursos, en este bloque, no están perfectamente definidos ni secuenciados y, además, no son demasiado coherentes con el objetivo pretendido que dice textualmente: valorar, diseñar y practicar actividades rítmicas con una base musical como medio de comunicación y expresión creativa.

En el bachiller, la Danza aparece como un procedimiento en el área de Educación Física. Este breve recorrido por los documentos oficiales, que recoge la normativa y la información necesaria para el desarrollo del área de Educación Artística en la educación primaria y de las áreas de Música y Educación Física en secundaria, muestra que la integración de la Danza en las enseñanzas de régimen general del Sistema Educativo carece de una propuesta clara, específica y coherente. Precisamente, a través de ese encuadramiento legal, se hacen explícitas las deficiencias y se revela la ausencia de un hilo conductor que sirva de guía para desarrollar los contenidos de la Danza en el proceso educativo de las enseñanzas de régimen general. El argumento de que es preferible hacer algo mejor que nada es parcialmente cierto; sin embargo, la falta de una perspectiva clara entorpece el buen funcionamiento del propio proceso. Conviene no pasar por alto otros problemas que también inciden negativamente en la enseñanza de la Danza a nivel educativo, son básicamente los referidos al desconocimiento de las aportaciones de la Danza al desarrollo integral de la persona, la idea generalizada de que la Danza es una actividad femenina y el gran problema de la formación de los profesores, sobre todo en el ámbito educativo, donde no todos los profesionales que la imparten en las áreas de Educación Física y Música tienen la formación necesaria, como aval de tal afirmación tenemos los planes de estudio que tienen que cursar dichos profesionales en sus carreras docentes.

Hablando en términos generales, la Danza en el sistema educativo no tiene el rango que se merece, en la actualidad esta materia aún se mantiene como una prolongación de la Educación Física y de la Educación Musical en la eseñanza obligatoria, siendo su carga lectiva insignificante. Con esto no queremos decir que la Danza deba desaparecer de los programas de Educación Física y de Música, pero compartimos con Robalo (1998) que el tratamiento que tiene la Danza en las enseñanzas de régimen general es reduccionista, como lo ilustran sus palabras:

Pero en rigor, de forma contradictoria, al considerar la Danza como forma de actividad eminentemente motora, se omitieron las habilidades, los conocimientos, los códigos, la terminología específica, por otro lado, al abogar a su originalidad y contribución única a nivel de la expresión, se confundió la Danza con la mera auto-expresión y no como refería Best (1985) la necesidad de dominar alguna disciplina, técnicas y criterios, inherentes al desarrollo de la capacidad creativa (p.64). 
HERMINIA GARCÍA RUSO

\section{Conlusiones}

El reto para el futuro está en la formación de profesionales cualificados. Es preciso, en todo caso, primero, que la Dramatización y la Danza formen parte de los contenidos curriculares de la formación de los profesores de educación primaria, y, segundo, que los titulados Superiores en Danza y Dramatización se ocupen de la formación de los futuros profesores en estas materias. Así, los profesores que impartieran el área de Educación Artística en la enseñanza primaria, deberían ser Maestros Especialistas en dicha área. Este plateamiento tiene su fundamentación en el enfoque globalizado que se le da a la Educación Artística en estas edades. En la educación secundaria, la Danza y la Dramatización no se contemplan en la LOGSE como áreas de conocimento obligatorias.

\section{Bibliografía}

GROSSMAN, P. (1990) The Making of a Teacher. Teacher Knowledge and Teacher Education. Chicago: Teacher College Press.

LEY ORGANICA 1/1990, de 3 de octubre, de Ordenación General del Sistema Educativo. BOE, 238, de 4 de octubre de 1990.

MARCELO,C. (1994) Formación del profesorado para el cambio educativo. Barcelona: PPV.

MEC (1989) Diseño Curricular Base. Educación Primaria.

MEC (1992a) Música. Secundaria Obligatoria.

MEC (1992b) Educación Física. Secundaria Obligatoria.

PÉREZ GÓMEZ, A. (1993) La formación del docente como intelectual comprometido, en Signos. Teoría y Práctica de la Educación, noo8 y 9, pp.42-53.

REAL DECRETO 1440/ 1991, de 11 de octubre, BOE no 244, pp. 33003 - 33018

REAL DECRETO 755/1992, de 26 de junio, BOE, no 178, pp. 25852 - 25854.

REAL DECRETO 1254/1997, de 24 de julio, BOE, no 212, pp. 26307 - 26318.

REAL DECRETO 1463/1999, de 17 de septiembre, BOE, no 233, pp. 34662 - 34670.

REAL DECRETO 3473/2000, de 29 de diciembre, BOE, oㅜ 14, p. 1810.

ROBALO, E. (1998) A Dança no Ensino Genérico: Problemas e perspectivas, en A. Macara (Ed.) Novas Tendencias no Ensino da Dança. Lisboa: F.M.H., pp. 56-62

SHULMAN, L.S. (1986) Those who understand: konwledge growth in teaching, in Educational Researcher, 15 (2); pp.4-14.

SHULMAN, L.S. (1987) Knowledge and teaching foundations of the new reforms, in Harvard Educational Review, 57 (1), pp.1-22.

SHULMAN, L.S. (1992) Renewing the Pedagogy of Teacher Education: The Impact of subject-Spcific Conceptions of Taching, en Motero, L y Vez, J.M. (Eds) Las Didácticas Específicas en la Formación del Profesorado. Santiago: Tórculo Ediciones, pp.53-69.

TINNING, R. (1992) Teacher Education and the Developement of Content Knowledge for Physical Educaction Teaching, en en Motero, L y Vez, J.M. (Eds) Las Didácticas Específicas en la Formación del Profesorado. Santiago: Tórculo Ediciones, pp. 535-554. 